Open Access

\title{
Triple Helix and academic entrepreneurial intention: understanding motivating factors for academic spin-off among young researchers
}

\author{
Altaf Hussain Samo ${ }^{*}$ and Noor UI Huda
}

* Correspondence:

altaf@iba-suk.edu.pk

EDC, Sukkur IBA University, Sindh, Pakistan

\begin{abstract}
Academic Spin-off is receiving a growing attention in entrepreneurship research due to increase in the number of ventures coming out from academia working at universities. The role of triple helix is key among many factors that derive young researchers to establish new venture as an outcome of their research. Thus, there is a need to determine the factors that derive young researchers for venture creation in order to identify and understand the determinants of Academic Entrepreneurial Intention (AEI) and how they are influenced by different helices of Triple Helix Model (THM). This study used sample of 310 young academic researchers studying/working in different universities of Pakistan. The finding of this study highlighted that government and academia have significantly positive relationship with the academic entrepreneurial intentions of young researchers while industry has positive, but insignificant relationship. The findings of this study have implication for promoting academic spin-off from developed and developing countries context.
\end{abstract}

Keywords: Triple Helix model (THM), Spin-off, Theory of planned behavioral (TPB), Academic entrepreneurial intentions (AEI)

\section{Introduction}

Innovation is one of the most valuable elements for economic growth and the welfare of the nation (Atkinson et al. 2012). Entrepreneurship is the main driving force behind the innovations nowadays. Due to such importance, scholars of entrepreneurship are paying more attention to academic spin-offs as one of the key elements of innovation at national level (Feola et al. 2017a, 2017b). Since many years many companies are developed through academic spin-off and their contribution to economic development has been clearly stated and a related intriguing about how entrepreneurial capabilities of the academia can be stimulated has developed (Obschonka et al. 2012). Our society is experiencing different challenges; knowledge becomes the most challenging imperative for solving any challenge. Correspondingly, there is an emerging body of literature which addressed the interaction between universities, industries and governments. Therefore, the concept of networking is not new in the practice. In a modern academic language, this concept is acknowledged as Triple Helix Model (THM). In the

(c) The Author(s). 2019 Open Access This article is distributed under the terms of the Creative Commons Attribution 4.0 International License (http://creativecommons.org/licenses/by/4.0/), which permits unrestricted use, distribution, and reproduction in any medium, provided you give appropriate credit to the original author(s) and the source, provide a link to the Creative Commons license, and indicate if changes were made. 
innovation process, the THM emphasized the importance of academia and government. In addition to that, these actors play a crucial role in the creation of entrepreneurial (Yurtkoru et al, 2014) society. This is why, Academic Entrepreneurial Intention (AEI) is considered fundamental. To start a new entrepreneurial adventure which is based on the outcome of academicians, research is considered a fascinating research issue and has recently attracted a growing number of researchers in entrepreneurship (Mosey; Ozgul and Kunday 2015). Academic literature has paid great attention towards understanding the characteristics of academic spin-offs and to the process behind their creation (Di Gregorio and Shane 2003; Grandi and Grimaldi 2005). However, limited research has been conducted for analyzing a subject involved in the academic field developing intention for new venture creation based on the results of his or her academic research (Feola et al. 2017a, 2017b; Prodan and Drnovsek 2010). Literature review shows various studies have been conducted to understand AEI (Clarysse et al. 2011; Meoli and Vismara 2016; Siegel and Wright, 2015). Despite a large number of literature on entrepreneurship intention, only a few studies on AEI focused on the determinants, and many of them did not even incorporate the role of government, industry and academia together. Based on the call from Siegel and Wright (2015), for rethinking on theoretical and empirical models of academic entrepreneurship, and suggestions (Feola et al. 2017a, 2017b) to understand AEI in the context of Triple Helix in different cultural settings to understand different helices impact on Academic Entrepreneurial Intention. This study incorporates the components of THM to operationalize the three helices of THM in predicting AEI from developing country perspective. For addressing this problem, the study on AEI in developing countries like Pakistan can have a huge impact to understand the commercialization of the innovations of young entrepreneur researchers and develop a platform to analyze how the intention of young entrepreneurs starts their own venture businesses which has a huge impact on society at large.

Thus, the goal of this study is to integrate the THM to understand the AEI from developing country perspective by testing the model to analyze the determinants of AEI. The study covers literature review in next section, and based on the literature review, it contains a proposed model for testing, testing of the model on the data collected from young researchers from different universities of Pakistan followed by findings, discussion on findings and conclusion.

\section{Literature review}

\section{Triple Helix model (THM)}

In entrepreneurial research study, the THM has been widely adopted to understand the innovation process based on entrepreneurial activities (Kim et al. 2012). THM is a basis for unfolding a representing relationship between government, industry and university for innovation. This model has been described as a cooperative relationship among research institutions, industry and government for promoting innovation in the era of knowledge based economy (Shin et al. 2012). The THM pivots on all helices that are interconnected and represents a national innovation system.

First, the governmental support at various levels has to be adopted for innovative start-ups. In particular, government is a central body to formulate the set of rules and normative conditions for the implementation of entrepreneurial activities. Similarly, the 
role of government also includes the provision of financial incentives and physical representation of incubators and science parks (Fini et al. 2011), that have been shown to be key elements in fostering entrepreneurship and process of innovation for start-ups. Second, helices of THM is the contribution of industry in the economy. Universities operate in a business environment become a useful resource for the development and growth of academic spin-offs (Fini et al. 2011). Numerous Studies have indicated that there is positive contribution of venture capital on the establishment of research and development, patents (Kortum and Lerner), developing professional attitude among start-ups (Hellmann and Puri, 2002), and resources access and competencies (Baum and Silverman, 2004). Moreover, financial support as well presence of industries in the region context can influence the creation of start-ups within economy (Klepper 2007). The presence of firms in the region working in the similar industries can facilitate the exchange of experiences, knowledge and information (Deeds, De Carolis, and Coombs, 1998). Third helices of THM is academia has to promote policies and instruments (Fini et al. 2011; Siegel; Veugelers, and Wright, 2007; Smilor and Gill, 1986) which are focused to promote the entrepreneurial intentions to become entrepreneurs and create a platform for academic spin-offs. Many studies highlighted that the supportive role of universities, which vary with regard to beneficiaries and the mobilization of resources.

In case of Pakistan, Triple Helix Model of university-industry-government (Etzkowitz et al. 2007) interaction for societal development is still at the stage of infancy. Recently the study is emerging in this field of promoting entrepreneurial intentions of young researchers towards venture creation. Moreover, the regional Triple Helix innovation is also a function of academic goals and objectives, trust among university, industry and government and the strength of local organizing and initiating capabilities. Nevertheless, knowledge spill-over increasingly occurs through commercialization of research results on campus, irrespective of societal or academic differences (Etkzowitz and Zhou, 2007). From developing and developed country perspective, Triple Helix is the physical device which succeeded in developing the university-industry-government interactions that have led to the creation of firm, the incubator, and the science centers and prop motion of Academic Entrepreneurship (Safiullin L.N; Fatkhiev A.M, 2014).

\section{Theory of planned behavior (TPB)}

This theory has envisaged from the field of psychology, used to predict the specific behavior of individual's towards attitudes. The TBP has three constructs of behavioral intentions include, attitude, subjective norms and perceived behavioral control, the intentions are responsible for the variation in actual behavior. The most important and useful theory according to the Lortie and Castrogiovanni (2015), is the TPB elaborated and has been used to predict the behavior of young entrepreneurs and their intentions to venture creation. The first one attitude defines that the person's desirability of performing a specific behavior. The second construct is Subjective norm defines that the pressing force from social groups including friends, family and peers encourages towards a specific behavior. Moreover, SN is focused on the beliefs of an individual about how they would be viewed by others and how it is socially acceptable within society. Furthermore, PBC defines that the personal beliefs of an individual about the 
convenience in performing that behavior. Among many models of AEI, the proved one and straightforward model is TPB than other models in predicting one's attitudes towards a specific behavior. In addition to that, this theory has used to predict various types of entrepreneurial intentions includes new firm creation and new venture development. (e.g., Kolvereid and Isaksen 2006; Krueger and Brazeal 1994; Liñán, Urbano, and Guerrero 2011).

From the context of THM, development of entrepreneurial intention among academicians can be very interesting investigation which has received little attention from researchers (Feola et al. 2017a, 2017b, Fini et al. 2012; Prodan and Drnovsek 2010). This implies to look at different helices of THM impact on academic entrepreneurial intentions.

\section{Academic entrepreneurial intention, TPB and THM}

The role of academic spin-off has been recognized as fundamental element for economic development in the literature (Di Gregorio and Shane 2003, Fini et al. 2017). However, the question about how the academic community's academic entrepreneurial potential can be stimulated is still unanswered (Fini et al. 2017; Fini, Obschonka et al. 2012; Fini, Grimaldi and Sobrero 2009). To understand impact on young academicians, AEI has got a lot of attraction in many entrepreneurship researchers (Fini et al., 2017; Goethner et al. 2012; Huyghe and Knockaert 2015; Mosey et al. 2012). According to Goethner et al. (2012), basing their study on the TPB, verified the ability of some economic variables to analyze AEI. However, in an academic context the main constructs of $\mathrm{EI}$ is the attitude, $\mathrm{PBC}$ and $\mathrm{SN}$, whereas economic variables indirectly influence on attitude and PBC (Fini et al., 2017). Several studies indicates that university culture and climate shape AEI (Huyghe and Knockaert 2015). It has been observed by many a scholars that the commitment of university to an entrepreneurial mission leads towards the more chances of EI of its academicians.

The scholars found that the more committed a university is to an entrepreneurial mission, there are the greater chances of entrepreneurial intention of its academicians. Moreover, it has been proved that technology transfer offices of universities have major contribution in developing entrepreneurial intention. Now days it has been observed that university has examined its propensity to create academic spin-offs and also determining student's propensity to startups (Bergmann et al. 2016; Fini et al. 2011). The formation of new firm is the ultimate result of the interaction between a person and its social surroundings. The theoretical suggestions from (Siegel and Wright 2015), that empirical rethink on university entrepreneurship, we propose an integration of society and environment with the theoretical models of personal behavior. To conclude that, we believe in the integration of THM and TPB that become a fruitful decision for the welfare of society.

The concepts represents one of the most popular models used to protecting specific behavior. There are three main constructs identified by TPB: attitude, SN and PBC. Attitude defines that the young entrepreneur researchers willingness to engage in a new firm creation. Another component is the subjective norms which state the external pressure from colleagues, peers, friends and family to perform a certain behavior, and in what perspective they would be viewed by other social groups if they are engaged in a particular behavior. Furthermore, $\mathrm{PBC}$ states that the personal beliefs about one's capacity to perform a particular behavior with ease or difficulty. 
This theory is used in a multiple areas of research, such as marketing and consumer behavior, tourism, health sciences, and leisure. The applications of TPB has been widely used in the research area of entrepreneurship and new venture creation (Liñán, Urbano, and Guerrero, 2011). From the above literature, we have proposed the following model of theoretical framework.

\section{Proposed model and research hypotheses (Fig. 1)}

Based on the literature review and previous studies, the hypotheses of this study.

Governmental support at various levels has to be adopted for innovative start-ups. It is a central body formulating policies and normative rules for establishing entrepreneurial environment (Fini et al., 2017), Moreover, government role is crucial in the provision of financial incentives and physical representation of science parks and incubators (Fini et al. 2011), which are the key elements in rearing entrepreneurship and process of innovation for start-ups. Therefore following hypothesis is formulated.

\section{H1: perceived support of government is positively related to AEI among young entrepreneur researchers.}

The 2nd helice of THM is the contribution of industry in the economy. Universities operate in a business environment become a useful resource of growth and development of academic spin-offs. Numerous Studies have indicated that there is positive contribution of industry role on the establishment of research, development, the number of patents and access to resources and competencies (Kortum and Lerner 2001). Furthermore, the influence of industries operating locally can stimulate the number of start-ups within economy (Fini et al., 2017).

Therefore following hypothesis is formulated.

H2: perceived support of industry is positively related to AEI among young entrepreneur researchers

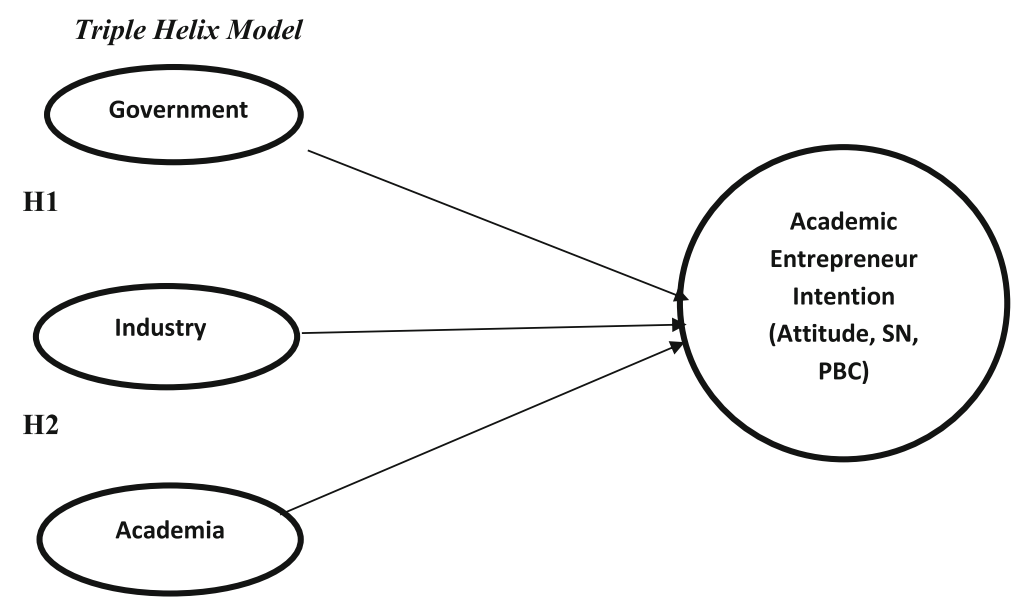

H3

Fig. 1 Conceptual Framework of This Study 
It has been indicated that the supportive role of universities changes accordingly to beneficiaries and mobilization of resources (Waas, Verbruggen and Wright, 2010). Universities has to setup the policies and instruments that aimed to develop a platform for academic spin- offs which can effect positively on the young researcher's behavior toward entrepreneurship (Fini et al. 2011).

Therefore following hypothesis is formulated.

H3: perceived support of university is positively related to AEI among young

entrepreneur researchers,

\section{Methodology}

\section{Research design}

This paper is based on the causal comparative and quantitative research design. The aim is to provide a clear understanding of the interaction among government, industry and academia on entrepreneurial intention of young researchers. In a structured questionnaire survey to obtain the particular data, 7-point Likert Scale has been used. The population of interest in this study is consisted of Pakistani young researchers enrolled in universities operating in all provinces of the country.

The sample includes the Ph.D. students who are currently enrolled in Ph.D. programs and doctors, who completed their Ph.Ds. in last 3 years. In this study, 350 questionnaires were randomly distributed in more than 30 universities of Pakistan out of which 310 were received back from which 40 were discarded. The data was analyzed by using quantitative approach.

\section{Data analysis techniques}

For data analysis, Structural Equation Modeling was used for hypothesis-testing in order to explain causality between variables. The assessment of the proposed Structural model was performed by implementing SmartPLS. The measurement of PLS model is based on the measurement of predictions through convergent validity having the loading values $>0.50$ (Chin, 1998a) and the value discriminant validity of Average Variance Extracted (AVE) of each construct. If the value of AVE is greater than the value of the correlation between the construct model discriminants, then it is said to have good validity (Fornell and Larcker, 1981). Moreover, for measuring reliability of the scale, Cronbach's alpha was used with a value $>0.6$ (Venkatraman et al, 2000), while the structural models were evaluated using R2 for the dependent construct, Stone-Geiser Q2 test for predictive relevance test and the t-test and the significance of the parameters of structural lines and criteria for measurement Tennanhaus GoF, where, Tenenhaus GoF $(\mathrm{GoF})=$ small $>=0.1$, medium $>=0.25$, large $>=0.36$ (Kock, 2012).

\section{Reliability and validity}

Cronbach's Alpha was implemented for validity and reliability analysis. The results indicated that the value of Cronbach's Alpha of the measurement scale of independent variables government, industry and academia greater than 0.8 and the value of dependent variable, AEI is also $>0.8$ which shows the internal reliability of the scale. Similarly, composite reliability should be $>0.8$ (Hair et al., 2013). The results of the analysis of 
entrepreneurial intention to Cronbach's Alpha, Composite Reliability and AVE are given in Table 5 in Appendix.

\section{Discriminant validity}

Discriminant validity has been tested and demonstrated in Table 6 in Appedix 1 that which shows the value of AVE of each construct is greater than the variance shared between the constructs; thus, it indicates the sufficient discriminant validity.

\section{Results}

Respondents' demographics

Table 1 summarizing the demographics of the study participants. The sample of respondents shows there are more females $64.5 \%$ than males $35.5 \%$. The sample of respondents belongs to a target population of young researchers. It shows that approximately $77 \%$ of the respondents are involved in a research program having less than 5 years of research experience, while $90 \%$ of total population lies between 25 and 35 years of age. The sample also contains a variety of occupational groups that includes, $28.1 \%$ are professionals working in universities, almost $6 \%$ are entrepreneurs, $21.3 \%$ are employees, $10 \%$ are non-professionals and above $34 \%$ are $\mathrm{PhD}$ students with no work experience.

\section{The predictive power of the model}

The summarized computed values for AEI is the dependent variable in the model. It determines $41.2 \%$ R2 for AEI considering the international and industrial research

Table 1 Respondents' demographics

\begin{tabular}{lll}
\hline Demographics & Frequency & Percentage \\
\hline Gender & 110 & 35.5 \\
Male & 200 & 64.5 \\
Female & & \\
Age & 126 & 40.6 \\
$20-25$ & 132 & 42.6 \\
$25-30$ & 31 & 10 \\
$30-35$ & 21 & 6.8 \\
$35-40$ & & 36.5 \\
Performed Research Activity & 113 & 40.3 \\
$1-2$ years & 125 & 11.9 \\
3-4 years & 37 & 7.7 \\
5-6years & 24 & 3.5 \\
7-8 years & 11 & \\
9-10 years & & 28.1 \\
Work Experience & 87 & 10 \\
Professional & 31 & 6.1 \\
Non-Professional & 19 & 21.3 \\
Entrepreneur & 66 & 34.5 \\
Employee & 107 & \\
No Experience & & \\
\hline
\end{tabular}


perspective, which also indicates that the R2 of 0.412 is greater than the acceptable threshold of 0.1 (Falk and Miller, 1992). Several largely experienced fit indices demonstrate that the measurement model fit the data well.

Table 2 illustrates that F2 analysis is the calculation of effect size, which complements R2 in the total impact size of the specific variables on dependent variables (Chin, 2010). The effect size calculation is based on the following formula: $f 2=$ ( $R 2$ included R2 excluded) / (1- R2included) (Cohen, 1988). The results of the study found that government support has small effect size $(\mathrm{f} 2=0.037)$ over Academic Entrepreneurial Intention. This shows that the government is lacking interest in investing academic research entrepreneurs. Similarly, industry was also determined with very small effect ( $\mathrm{f} 2=0.001$ ), and it is due to lower contribution of Academic Entrepreneurs within the Pakistani industries; however, the determined effect size for academia ( $\mathrm{f} 2=0.104$ ) is overall a larger effect size on Academic Entrepreneurial Intention, because academia is actively promoting Academic Entrepreneurs to contribute within society with their research and novel ideas to respond the emerging issues of the society. Hence, the Table 2 above summarizes the effect sizes of each of the latent variables.

In this study the analysis of predictive relevance of the AEI, a dependent variable is also carried out. Therefore, blindfolding test was used to calculate the cross-validated redundancy Q2 blindfolding test was used (Fornell \& Cha, 1994) as demonstrated in Table 2, the blindfolding test indicated the value of Q2 for latent construct should be > zero, which is 0.399; this suggests the predictive relevance of the model (Chin, 1998b).

\section{Hypothesis results}

The investigation of the relationship among variables was assessed by running the overall structural model. Several indices demonstrated that the selected model in this study well fit the data. Maximum-likelihood estimates for various parameters, and the overall fit of the proposed model reported in Tables 2 and 3 (Fig. 2).

Table 4 summarizes the relationship of the constructs that was analyzed by using Smart PLS 0.30. The maximum calculation was demonstrated that the parameter to fit the proposed model. The result indicate that hypotheses $\mathrm{H} 1$ to $\mathrm{H} 3$ pertain to the influence of the triple helix components and AEI. It also showed that the relationship between the both, government support and university support was tested with AEI. The results indicate that government support (beta $=0.232$, $\mathrm{t}$-value $=2.968$, and $p=0.002$ ), which suggested that $\mathrm{H} 1$ is supported. It also the indicated that government of Pakistan policy for taking initiatives to encourage the young researcher entrepreneurs and provide sufficient funding for the incubators within universities having positive impact. This indicates that government support has significant influence on the AEI of young researchers. Similarly, Industry support was tested with respect to the relationship

Table 2 Effect sizes of latent variables

\begin{tabular}{llll}
\hline & $\mathrm{R} \wedge 2$ & $f \wedge 2$ & Effect size rating \\
\hline Entrepreneurial Intention & 0.412 & & \\
Government & - & 0.037 & small effects \\
Industry & - & 0.001 & very small effects \\
Academia & - & 104 & large effects \\
\hline
\end{tabular}


Table 3 Blindfolding results

\begin{tabular}{lllc}
\hline & SSO & SSE & Qᄀ? (=1-SSE/SSO) \\
\hline AEI & 2170.000 & 1304.05 & 0.399 \\
\hline
\end{tabular}

between Industry and AEI., which reveals statistically insignificant (beta $=0.037$, $\mathrm{t}$-value $=0.472, p=0.318$ ). This indicate that industry and university relationship are not up to the mark for promoting AEI among young researchers. Academia support was tested with respect to its relationship with Academic Entrepreneurial Intention having (beta $=0.421$, $\mathrm{t}$-value $=5.161, p=0.000$ ). It indicate that Academia has positive and significant effect on AEI. It indicates that the role of universities is very encouraging and positive on young researcher for encouraging academic spin-off. This means that Academia supports young researchers by providing them a platform where they can start their new venture based on research. It also improves the quality of young researchers to become reliable and useful entrepreneurs and contribute to the economic welfare of the country. In addition to that, the result also shows $\mathrm{R}^{\wedge} 2$ for Academic Entrepreneurial Intention is 0.412 which indicates that the variables in the study explained $41.2 \%$ of the variance of the Academic Entrepreneurial Intention and remaining $58.8 \%$ is explained by other variables, which are not included in this study.

\section{Discussion}

The purpose of this study is to analyze the influence of triple helix model on the academic entrepreneurship in the Pakistani universities. The conceptual framework of this model suggests that $41.2 \%$ of the variance of AEI has surpassing the explained variance in previous studies on AE. (Fernández-Pérez et al., 2014). The theme of AEI is a very interesting, yet a little explored area of the research. The first aim of the study is to develop a model aimed at exploring the determinants of AEI. Thus, the extension of the TPB is proposed in this study, integrating the three helices of the THM. The second aim of this study is to develop an operationalization and a measurement scale of the three helices of the THM: government, industry and academia.

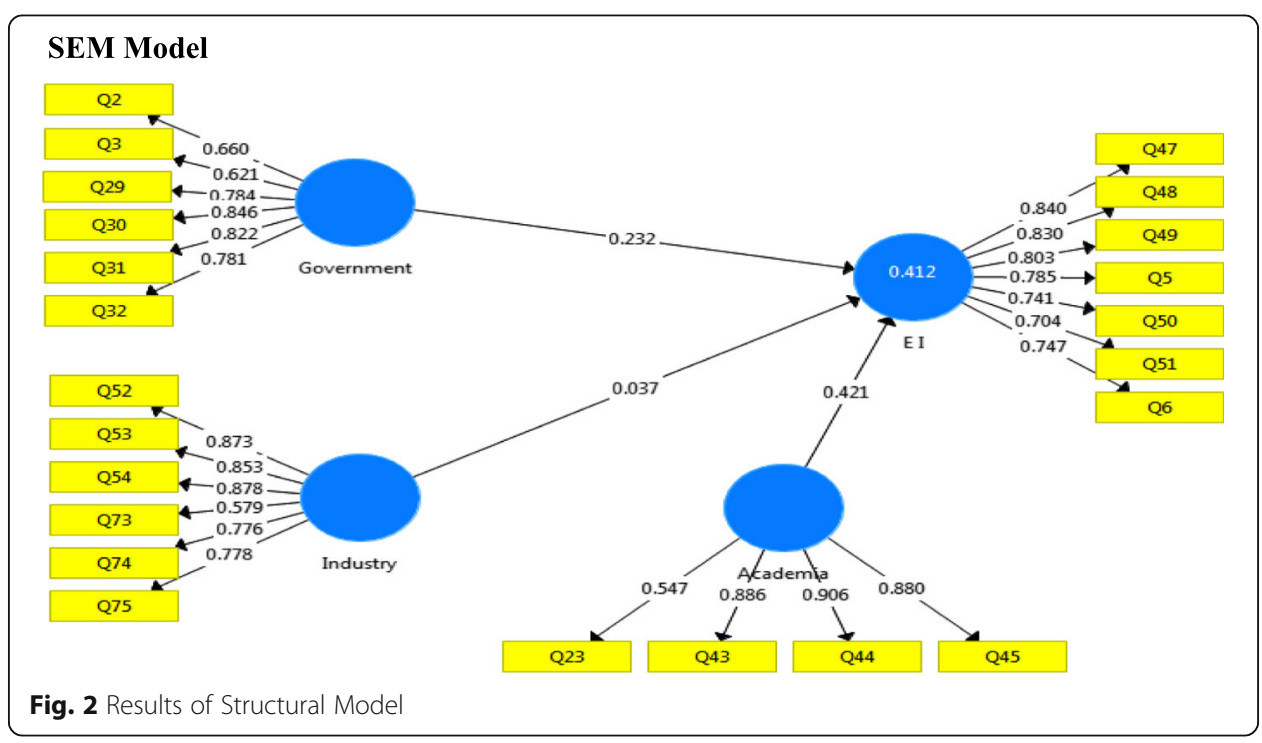


Table 4 Path coefficients and hypothesis testing

\begin{tabular}{llllll}
\hline Hypothesis & Relationship & Path coefficient & T-statistics & $P$ values & Decision \\
\hline H1 & Government support - > AEI & 0.232 & 2.968 & $0.002^{* * *}$ & Supported \\
$\mathrm{H} 2$ & Industry support - > AEI & 0.037 & 0.472 & 0.318 & Not Supported \\
$\mathrm{H} 3$ & Academia - > AEl & 0.421 & $\mathrm{SS5.161}$ & $0.000^{* * *}$ & Supported \\
${ }^{* * *} p<0.01 ;{ }^{* *} p<0.05$ & & & &
\end{tabular}

The empirical evidence for the effects of Triple Helix Model that includes Government, Industry and Academia on Academic Entrepreneurial Intentions revealed out some encouraging aspects that influence the intention of young entrepreneur researchers intention of that the academic background of the researchers has an influence on pursuing their career choice based on entrepreneurship in the future. The level of education also increases the chances of venturing entrepreneurship. Because the soaring level of unemployment, most of the students have launched their own businesses for that they need higher education to incorporate more novel and innovative ideas for new venture firm creation.

The above mentioned results of this study indicate that government support is significantly related to the AEI is another key element for fostering the Academic Entrepreneurial Intentions of young researchers which are consistent with the findings of (Fini et al., 2017, Audretsch, Grilo, and Thurik 2007). These results are providing supporting signals to the Government of Pakistan's initiatives for encouraging the young researchers for funding new research programs and supporting the incubators within universities. Government of Pakistan through Higher Education Commission (HEC) has also enhanced a number of research programs, technology park funding, research grants, and ORIC and establishing incubation center at universities. This helps in determining young researchers' attitude and belief in government policies and motivates them towards spin-off the new venture from their research.

Second, the relationship between the Industry support and AEI does not have any direct effect on AEI. This result is somewhat contrast with a lot of studies, and in consistence with finding of (Fini e tal., 2017). These results are indication of weak academia and industry linkages in Pakistan. The results also indicate that the academic research work exists in separate SILO's within Pakistani context (Gul and Ahmad 2012). Therefore, in Pakistan, promoting entrepreneurship within industrial sector is gradually evolved. Moreover, for academic community it is important to focus on knowledge sharing and transferring within industries. This can be done by promoting and sharing the scientific activities and research work within industrial sector of Pakistan in order to get insights and relevant information about trends and needs of industry.

Finally, the role of academia is fostering a change in this environment by promoting a culture that includes entrepreneurial activities as a part of the academic professional curriculum. Undoubtedly, business school education will be geared towards startups and innovativeness to foster entrepreneurship (Plaschka and welsch, 1990: Solomon and fernald, 1991). The role of academia is very positive and encouraging the young researchers to choose their career choice as an entrepreneur. For that reason, from faculty to higher education commission (HEC) supports young entrepreneurs to get enrolled in Ph.D. to make them able to do research and work in the real projects that practically serve in the society. In addition to that, this study also reveals that the female academic researchers are more eager to start their business than their male 
counterparts. Thus, the role of academia is very positive and encouraging for the young researchers to choose their career choice as an entrepreneur.

This is the first study of its kind to propose in Pakistani context to test a comprehensive scale which integrated all the THM helices. In this study, a "Triple Helix" measurement scale was refined and build on existing scales with the aim to test the relevance of each component of entrepreneurial intention (Fini et al. 2012; Fini et al. 2009). The relevance of the different factors in government, university, and industry are also influencing entrepreneurial intention of young re- searchers. Therefore, this study have implications for governments, industrial sector and universities that can be aimed to stimulate the entrepreneurial orientation of young academicians.

\section{Implications}

From theoretical point of view, the study instigates the multiple variables of TPB and THM to assess the impact on AEI. The literature on AEI has mainly focused on psychological and individual factors that have ignored the integration between TPB and THM in order to analyze the impact of AEI. Secondly, the study is operationalizing Triple Helix approach for the first time to provide a better analysis of the helices (Fini et al. 2012; Fini et al. 2009). From the practical point of view, this is the first study conducted in developing country, Pakistan, which introduced the relationship of THM and its integration of three variables, Government, Industry and Academia support, are shaping the attitude towards AEI of young researchers. This study also focused on several implications given below for three helices. According to (GEM) report of Pakistan 2017, only 4.7\% businesses are well established, which is less than the average rate for factor-driven economies (12.6\%). This rate shows that entrepreneurs in Pakistan are less enthusiastic to embrace the change to improve their economic conditions. For this reason, government takes measures to support the SMEs and MSMEs in order to respond poor economic conditions of the country. In case of industry, it is inducting technical manpower, which only addresses the specific or special issues of its operations therefore, researchers remained ignorant and creating jobs for themselves.

In addressing above mentioned grey areas which are bottleneck in promoting the culture of entrepreneurship which encourage academic spin offs. Government and academia need to work together for identifying the policy level measure and implementation strategy for developing entrepreneurial ecosystem at university level which facilitate entrepreneurial activities and academic spinoff. Moreover, government also need to develop policies which encourage new startups based on the results of research and directly supporting new ventures through specific regional programs (Fini et al. 2011). There is also need to develop interaction between academia and industry that operate in the same region. The interest of young academician's and natural exchange of ideas with industry can help in developing closer interaction which may lead to understand industry requirement and direct activities and entrepreneurial ideas according to the need of local industry. Universities with the help of government can also facilitate young researchers through ORIC and/or technology transfer offices for promoting the research activities at regional and national that target local industry. 


\section{Limitation and suggestion for future research}

This study has several limitations that definitely open up avenues for further research. First, the target audience of this study was based on a sample of Ph.D. students located in a confined geographic areas of different provinces of Pakistan. The model's validity is being assessed at a national level, but this research is not being compared with other developing nations because of limited study that has been done in developing countries to promote the culture of Academic Entrepreneurial Intentions of young researchers.

Second, in previous studies (Garcia-Rodriguez et al. 2015; De Pillis and De Reardon 2007) it has been noted that cultural differences very much influence the Entrepreneurial Intention. This study does not highlight the cross-cultural comparison in its findings, and for that the model of this study could be tested using the data from universities in different developing countries.

Third, it was also noted that recent literature underlined the multifaceted aspects of university in local context supported AEI (Fini et al. 2011; Meoli and Vismara 2016). Therefore, an in-depth analysis of how various types of facilitations have been realized and how they concretely influence AEI is needed for further research. The Triple Helix variables explained only $41.2 \%$ variance in AEI of young researchers. Hence, the future research requires to include some variables that can influence the entrepreneurial intention on researchers. The data was also collected from Pakistani universities; therefore, to further validate the entrepreneurial intention on young researchers, the data to be collected from other developing countries to compare and validate the three helix impact on academic entrepreneurial intentions from developing country perspective.

\section{Conclusion}

The area of research on academic EI of young researchers is little explored. This study is based on the integration of psychological aspects of TPB with the three helices of the THM. Moreover, the results of this study shows that academia is the most important determinant of shaping attitude towards entrepreneurial intention. The results of this study indicates that two out of three helix variables, government and academia, H1 and H3, have a significant and positive impact on the Academic Entrepreneurial Intentions, whereas H2, support from Industry has an insignificant relationship to AEI. This study suggest the integration of the three helices of THM on comprehensive scale for understanding academic entrepreneurial intentions. Universities are promoting entrepreneurship that contributes in triple helix configurations and developing AEI. However, there is the need of collaboration between academia and government for promoting academic incubator facilities at universities and develop technology-transfer infrastructures that represents the contributions of academia in the formation of new venture business creation from the results of young entrepreneur researchers. This study also indicate that Industry support does not shape the intentions of young researchers towards entrepreneurial behavior in developing countries like Pakistan because of weak Industry-Academia ties in labor market. This is due to industry and academia relation are gradually evolving in Pakistan they need to work together for promoting the culture research and innovation for promoting entrepreneurship. Moreover, there is need of close interaction between industry and academia to get greater number of academic spin-offs which is the key element for innovation and economic development at national level. 


\section{Appendix}

Table 5 Reliability and validity

\begin{tabular}{|c|c|c|c|c|c|}
\hline Variables & Items & Loadings & AVE & Cronbach's Alpha & Composite Reliability \\
\hline \multirow[t]{7}{*}{ Government } & & & 0.573 & 0.849 & 0.888 \\
\hline & GS 2 & 0.660 & & & \\
\hline & GS 3 & 0.621 & & & \\
\hline & GS 29 & 0.784 & & & \\
\hline & GS 30 & 0.846 & & & \\
\hline & GS 31 & 0.822 & & & \\
\hline & GS 32 & 0.781 & & & \\
\hline \multirow[t]{7}{*}{ Industry } & & & 0.634 & 0.883 & 0.911 \\
\hline & Ind 52 & 0.873 & & & \\
\hline & Ind 53 & 0.853 & & & \\
\hline & Ind 54 & 0.878 & & & \\
\hline & Ind 73 & 0.579 & & & \\
\hline & Ind 74 & 0.776 & & & \\
\hline & Ind 75 & 0.778 & & & \\
\hline \multirow[t]{5}{*}{ Academia } & & & 0.670 & 0.820 & 0.887 \\
\hline & Acd 23 & 0.547 & & & \\
\hline & Acd 43 & 0.886 & & & \\
\hline & Acd 44 & 0.906 & & & \\
\hline & Acd 45 & 0.880 & & & \\
\hline \multirow[t]{8}{*}{ AEl } & & & 0.608 & 0.892 & 0.915 \\
\hline & AEI 5 & 0.785 & & & \\
\hline & AEI 6 & 0.747 & & & \\
\hline & AEl 47 & 0.840 & & & \\
\hline & AEl 48 & 0.830 & & & \\
\hline & AEl 49 & 0.803 & & & \\
\hline & AEI 50 & 0.741 & & & \\
\hline & AEI 51 & 0.704 & & & \\
\hline
\end{tabular}

Table 6 Discriminant validity assessment

\begin{tabular}{|c|c|c|c|c|}
\hline Latent variable correlations & Academia & AEl & Government & Industry \\
\hline Academia & $0.818^{*}$ & & & \\
\hline AEI & 0.621 & $0.780^{*}$ & & \\
\hline Government & 0.744 & 0.570 & 0.757 & \\
\hline Industry & 0.739 & 0.506 & 0.682 & $0.796^{*}$ \\
\hline
\end{tabular}

*Value of AVE of each construct is greater than the variance shared between the constructs; thus, it indicates the sufficient discriminant validity 


\section{Abbreviations}

AEl: Academic Entrepreneurial Intention; AVE: Average variance extracted; GEM: Global entrepreneurship monitor; GS: Government support; IS: Industry support; MSMES: Micro, small and medium enterprises; PBC: Perceived behavioral control; SMEs: Small and medium enterprises; SN: Subjective norms; THM: Triple helix model; TPB: Theory of planned behavior

\section{Acknowledgements}

We would like to acknowledge the Professor Massimiliano Vesci from UNISA, Italy for allowing us to adapt the questionnaire developed by their team for the research purpose.

\section{Funding}

There is no funding body which has financed this research project. Sukkur IBA University helped us in the data collection process by allowing us to draw TA/DA for traveling and lodging.

\section{Availability of data and materials}

The datasets generated and/or analyzed during the current study are not publicly available We are still working on another aspect and intend to develop another paper] but are available from the corresponding author on reasonable request.

\section{Authors' contributions}

Study conception and design: AHS. Acquisition of data: NUH and AHS. Analysis and interpretation of data: NUH and AHS. Drafting of manuscript: AHS and NUH. Critical revision: AHS. All authors read and approved the final manuscript.

\section{Competing interests}

The authors declare that they have no competing interests.

\section{Publisher's Note}

Springer Nature remains neutral with regard to jurisdictional claims in published maps and institutional affiliations.

Received: 3 August 2018 Accepted: 21 November 2018

Published online: 14 January 2019

\section{References}

Atkinson, A., \& Messy, F. A. (2012). Measuring financial literacy.

Audretsch, D. B., Grilo, I., \& Thurik, A. R. e. (2007). Handbook of research on entrepreneurship policy. Edward Elgar Publishing.

Baum, J. A., \& Silverman, B. S. (2004). Picking winners or building them? Alliance, intellectual, and human capital as selection criteria in venture financing and performance of biotechnology startups. Journal of business venturing, 19(3), 411-436.

Bergmann, H., Hundt, C., \& Sternberg, R. (2016). What makes student entrepreneurs? On the relevance (and irrelevance) of the university and the regional context for student start-ups. Small Business Economics, 47(1), 53-76.

Chin, W. W. (1998a). Commentary: Issues and opinion on structural equation modeling.

Chin, W. W. (1998b). The partial least squares approach to structural equation modeling. Modern methods for business research, 295(2), 295-336.

Chin, W. W. (2010). How to write up and report PLS analyses. In Handbook of partial least squares (pp. 655-690). Berlin, Heidelberg: Springer.

Clarysse, B., Tartari, V., \& Salter, A. (2011). The impact of entrepreneurial capacity, experience and organizational support on academic entrepreneurship. Research Policy, 40(8), 1084-1093.

Cohen, J. (1988). Statistical power analysis for the behavioral sciences 2nd edn.

De Pillis, E., \& Reardon, K. K. (2007). The influence of personality traits and persuasive messages on entrepreneurial intention: A cross-cultural comparison. Career Development International, 12(4), 382-396.

Deeds, D. L., DeCarolis, D., \& Coombs, J. E. (1998). Firm-specific resources and wealth creation in high-technology ventures: Evidence from newly public biotechnology firms. Entrepreneurship Theory and Practice, 22(3), 55-73.

Di Gregorio, D., \& Shane, S. (2003). Why do some universities generate more start-ups than others? Research policy, 32(2), 209-227.

Etzkowitz, H., \& Zhou, C. (2007) Regional innovation initiator: the entrepreneurial university in various triple helix models. In Singapore Triple Helix VI Conference Theme Paper (pp. 1-25).

Falk, R. F., \& Miller, N. B. (1992). A primer for soft modeling. University of Akron Press.

Feola, R., Vesci, M., Botti, A., \& Parente, R. (2017a). The determinants of entrepreneurial intention of young researchers: Combining the theory of planned behavior with the triple Helix model. Journal of Small Business Management.

Feola, R., Vesci, M., Botti, A., \& Parente, R. (2017b). The determinants of entrepreneurial intention of young researchers: Combining the theory of planned behavior with the triple Helix model. Journal of Small Business Management, 2017. https://doi.org/10.1111/jsbm.12361.

Fernández-Pérez, V., Esther Alonso-Galicia, P., del Mar Fuentes-Fuentes, M., \& Rodriguez-Ariza, L. (2014). Business social networks and academics' entrepreneurial intentions. Industrial Management \& Data Systems, 114(2), 292-320.

Fini, R., Fu, K., Mathisen, M. T., Rasmussen, E., \& Wright, M. (2017). Institutional determinants of university spin-off quantity and quality: a longitudinal, multilevel, cross-country study. Small Business Economics, 48(2), 361-391.

Fini, R., Grimaldi, R., Marzocchi, G. L., \& Sobrero, M. (2012). The determinants of corporate entrepreneurial intention within small and newly established firms. Entrepreneurship: Theory and Practice, 36(2), 387-414.

Fini, R., Grimaldi, R., Santoni, S., \& Sobrero, M. (2011). Complements or substitutes? The role of universities and local context in supporting the creation of academic spin-offs. Research Policy, 40(8), 1113-1127. 
Fini, R., Grimaldi, R., \& Sobrero, M. (2009). Factors fostering academics to start up new ventures: an assessment of Italian founders' incentives. The Journal of Technology Transfer, 34(4), 380-402.

Fornell, C., \& Larcker, D. F. (1981). Structural equation models with unobservable variables and measurement error: Algebra and statistics. Journal of marketing research, 382-388.

Fornell, C., Larcker, D. F., \& Cha, J. (1994). "Partial Least Squares,". Advances Methods of Marketing Research (pp. 52-78).

Garcia-Rodriguez, F. J., Gil-Soto, E., Ruiz-Rosa, I., \& Sene, P. M. (2015). Entrepreneurial intentions in diverse development contexts: A cross-cultural comparison between Senegal and Spain. International Entrepreneurship and Management Journal, 11(3), 511-527.

Goethner, M., Obschonka, M., Silbereisen, R. K., \& Cantner, U. (2012). Scientists' transition to academic entrepreneurship: Economic and psychological determinants. Journal of Economic Psychology, 33(3), 628-641.

Grandi, A., \& Grimaldi, R. (2005). Academics' organizational characteristics and the generation of successful business ideas. Journal of Business Venturing, 20(6), 821-845.

Gul, A., \& Ahmad, A. (2012). Perspectives of academia-industrial linkage in Pakistan: An insight story. Science, Technology and Development, 31(2), 175-182.

Hair, J. F., Ringle, C. M., \& Sarstedt, M. (2013). Partial least squares structural equation modeling: Rigorous applications, better results and higher acceptance.

Hellmann, T., \& Puri, M. (2002). Venture capital and the professionalization of start-up firms: Empirical evidence. The journal of finance, 57(1), 169-197.

Huyghe, A., \& Knockaert, M. (2015). The influence of organizational culture and climate on entrepreneurial intentions among research scientists. The Journal of Technology Transfer, 40(1), 138-160.

Kim, Y., Kim, W., \& Yang, T. (2012). The effect of the triple Helix system and habitat on regional entrepreneurship: Empirical evidence from the US. Research Policy, 41(1), 154-166.

Klepper, S. (2007). Disagreements, spinoffs, and the evolution of Detroit as the capital of the US automobile industry. Management Science, 53(4), 616-631.

Kock, N. (2012). WarpPLS 3.0 user manual. Laredo: ScriptWarp Systems.

Kolvereid, L., \& Isaksen, E. (2006). New business start-up and subsequent entry into self-employment. Journal of Business Venturing, 21(6), 866-885.

Kortum, S., \& Lerner, J. (2001). Does venture capital spur innovation? In Entrepreneurial inputs and outcomes: New studies of entrepreneurship in the United States (pp. 1-44). Bingley: Emerald Group Publishing Limited.

Krueger, N. F., Jr., \& Brazeal, D. V. (1994). Entrepreneurial potential and potential entrepreneurs. Entrepreneurship theory and practice, 18(3), 91-104.

Liñán, F., Urbano, D., \& Guerrero, M. (2011). Regional variations in entrepreneurial cognitions: Startup intentions of university students in Spain. Entrepreneurship and Regional Development, 23(3-4), 187-215.

Lortie, J., \& Castrogiovanni, G. (2015). The theory of planned behavior in entrepreneurship research: What we know and future directions. International Entrepreneurship and Management Journal, 11(4), 935-957.

Meoli, M., \& Vismara, S. (2016). University support and the creation of technology and non-technology academic spin-offs. Small Business Economics, 47(2), 1-18.

Mosey, S., Noke, H., \& Binks, M. (2012). The influence of human and social capital upon the entrepreneurial intentions and destinations of academics. Technology Analysis and Strategic Management, 24(9), 893-910.

Obschonka, M., Goethner, M., Silbereisen, R. K., \& Cantner, U. (2012). Social identity and the transition to entrepreneurship: The role of group identification with workplace peers. Journal of Vocational Behavior, 80(1), 137-147.

Ozgul, U., \& Kunday, O. (2015). Conceptual development of academic entrepreneurial intentions scale. Procedia-Social and Behavioral Sciences, 195, 881-887.

Plaschka, G. R., \& Welsch, H. P. (1990). Emerging structures in entrepreneurship education: Curricular designs and strategies. Entrepreneurship theory and Practice, 14(3), 55-71.

Prodan, l., \& Drnovsek, M. (2010). Conceptualizing Academic-Entrepreneurial Intentions: An Empirical Test. Technovation, 30(5), 332-347.

Safiullin, L. N., Fatkhiev, A. M., \& Grigorian, K. A. (2014). The triple helix model of innovation. Mediterranean Journal of Social Sciences, 5(18), 203.

Shin, J. C., Lee, S. J., \& Kim, Y. (2012). Knowledge-based innovation and collaboration: a triple-helix approach in Saudi Arabia. Scientometrics, 90(1), 311-326.

Siegel, D. S., Veugelers, R., \& Wright, M. (2007). Technology transfer offices and commercialization of university intellectual property: performance and policy implications. Oxford review of economic policy, 23(4), 640-660.

Siegel, D. S., \& Wright, M. (2015). Academic entrepreneurship: time for a rethink? British Journal of Management, 26(4), 582-595.

Smilor, R. W., \& Gill, M. D., Jr. (1986). The New Business Incubator: Linking Talent, Technology. Capital, and Know-how.

Solomon, G. T., \& Fernald, L. W., Jr. (1991). Trends in small business management and entrepreneurship education in the United States. Entrepreneurship theory and practice, 15(3), 25-40.

Venkatraman, R. C., Chern, V. M. H., Nanja, S., Gujarathi, H., \& Corp, P. X. (2000). E-mail program capable of transmitting, opening and presenting a container having digital content using embedded executable software. US Patent, 6, 014,688,

Waas, T., Verbruggen, A., \& Wright, T. (2010). University research for sustainable development: definition and characteristics explored. Journal of cleaner production, 18(7), 629-636.

Yurtkoru, E. S., Kuşcu, Z. K., \& Doğanay, A. (2014). Exploring the antecedents of entrepreneurial intention on Turkish University students. Procedia-Social and Behavioral Sciences, 150, 841-850. 